\title{
Spray Pyrolytic Deposition of Zirconium Oxide Thin Films: Influence of Concentration on Structural and Optical Properties
}

\author{
Mangesh Waghmare, ${ }^{1,2}$ Pratik Sonone, ${ }^{1}$ Prashant Patil, ${ }^{3}$ Vishal Kadam, ${ }^{2}$ Habib Pathan ${ }^{2}$ and Ashok Ubale ${ }^{1 *}$
}

Zirconium oxide $\left(\mathrm{ZrO}_{2}\right)$ thin films were deposited by spray pyrolysis technique using precursor solution of zirconyl chloride octahydrate $\left(\mathrm{ZrOCl}_{2} \cdot 8 \mathrm{H}_{2} \mathrm{O}\right)$ on glass substrate at $450{ }^{\circ} \mathrm{C}$. The effects of concentration of precursor solution on the structural and optical properties of $\mathrm{ZrO}_{2}$ films were investigated. The films were characterized by X- ray diffraction (XRD), Scanning electron microscopy (SEM), Energy-dispersive Xray spectroscopy (EDX), Transmission electron microscopy (TEM), UV-vis analysis and Fourier transform infrared (FT-IR) spectroscopy. The films were amorphous in nature at $0.025 \mathrm{M}$ concentration and it was observed that crystallinity increases with increase in concentration of precursor solution. The crystalline films exhibited cubic zirconium oxide $\left(c-\mathrm{ZrO}_{2}\right)$ phase. The surface morphology of the films was strongly influenced by the concentration of the precursor solution. The EDX study confirmed the existence of $\mathrm{Zr}$ and O. The TEM images showed nanosized as well as agglomerated $\mathrm{ZrO}_{2}$ particles with the average particle size $<20 \mathrm{~nm}$. The well-crystallized cubic phase of the films was further enlightened by selected area electron diffraction patterns. The UV-vis study showed that the optical band gap values were decreased with decrease in concentration of precursor solution. The formation of zirconium oxide was further confirmed by FT-IR spectroscopy.

Keywords: Nanostructured thin films; Zirconium oxide; Cubic zirconia; Spray pyrolysis

Received 3 October 2018, Accepted 15 November 2018

DOI: $10.30919 / \mathrm{es} 8 \mathrm{~d} 622$

\section{Introduction}

Zirconium oxide thin films have acquired considerable attention in the variety of applications such as protective coatings, insulating dielectric layers, catalysts, sensors and fuel cells as the properties of the films are found to be dependent on the growth conditions and methods of synthesis. Many efforts have been put in the development of low cost techniques which can offer the desired optical and structural characteristics of the material. $\mathrm{ZrO}_{2}$ has been rigorously studied from the past few decades because of its distinct properties like high chemical inertness, low thermal conductivity, high dielectric constant, high transparency in the visible and near infrared region and high refractive index." 2 Several methods have been employed for the deposition of $\mathrm{ZrO}_{2}$ thin films which include sputtering, ${ }^{3}$ spin coating, ${ }^{4}$ sol-gel, ${ }^{5}$ radio-frequency sputtering, ${ }^{6}$ pulsed laser deposition, ${ }^{7}$ metal-organic chemical vapour deposition ${ }^{8}$ and spray pyrolysis.' However, spray pyrolysis has become one of the preferred methods for the deposition of thin transparent oxide layers due to some of its distinct advantages such as lower crystallization temperature, homogeneity,

${ }^{I}$ Nanostructured Thin Film Materials Laboratory, Department of Physics, Govt. Vidarbha Institute of Science and Humanities, Amravati 444604, India

${ }^{2}$ Advanced Physics Laboratory, Department of Physics, Savitribai Phule Pune University, Pune - 411007, India

${ }^{3}$ Sinhgad Institute of Technology, Lonavala - 410401, India

*E-mail:ashokuu@yahoo.com simplicity, excellent compositional control and cost effectiveness.

Ruiz et $a l^{10}$ have obtained zirconia films by spray pyrolysis technique and investigated the effects of composition of substrate (carbon steel, stainless steel, alumina and borosilicate glass), time (1 and $2 \mathrm{~h}$ ), temperature $\left(450{ }^{\circ} \mathrm{C}\right.$ and $\left.650{ }^{\circ} \mathrm{C}\right)$, and carrier gas (Ar, N, He and air) on characteristics of the films. Stelzer and Schoonman ${ }^{11}$ have deposited zirconium oxide films by spray pyrolysis using $\mathrm{Zr}$ acetylacetonate $\left[\left(\mathrm{Zr}_{(}\left(\mathrm{C}_{5} \mathrm{H}_{5} \mathrm{O}_{2}\right)_{4}\right]\right.$ as precursor. Peshev et al. ${ }^{12}$ have used oxalic acid and zirconyl chloride octahydrate to prepare a precursor solution. The study showed that the spray pyrolytic deposited films on silica substrate were amorphous in nature. On heat treatment, cubic zirconia phase was detected in the films at temperatures $\mathrm{T}=500-700$ ${ }^{\circ} \mathrm{C}$. Both cubic and monoclinic phases were detected as temeperature rises from $700-1000{ }^{\circ} \mathrm{C}$. The $c-\mathrm{ZrO}_{2}$ content decreases with increase in temperature. Ortiz et al..$^{13}$ have deposited zirconium oxide films onto fused quartz and silicon in the temperature range of $300 \mathrm{C}$ to $575{ }^{\circ} \mathrm{C}$ by the pyrosol process using precursor solution of zirconium acetylacetonate. The films were found to be amorphous in nature below $425{ }^{\circ} \mathrm{C}$. The cubic crystalline phase was observed for short deposition times and higher temperatures. The films showed monoclinic crystalline phase for long deposition times. Ramos-Guerra et al..$^{14}$ have studied structural and photoluminescence properties of un-doped and $\mathrm{ZrO}_{2}$ films doped with $\mathrm{Tb}^{3+}$ and $\mathrm{Eu}^{3+}$ ions by ultrasonic spray pyrolysis technique. The XRD study demonstrated the polycrystalline nature and the existence of tetragonal metastable phase of the films. They revealed that the deposition temperature decides the surface morphological characteristics of the films. The photoluminescence analyses of the films presented a broad emission peak associated with radiative transition 
within $\mathrm{ZrO}_{2}$ matrix at $440 \mathrm{~nm}$ as well as characteristic emission peaks associated with $\mathrm{Eu}^{3+}$ and $\mathrm{Tb}^{3+}$ ions. Also, it was noticed that the intensity of the photoluminescence emission increases with increase in deposition temperature. Jothibas et al. ${ }^{15}$ have deposited $\mathrm{ZrO}_{2}$ thin films at various substrate temperatures in the range $275-475{ }^{\circ} \mathrm{C}$. The XRD study demonstrated that the crystallite size of the films increases with increase in substrate temperature. Further, the study confirmed the tetragonal phase of $\mathrm{ZrO}_{2}$. The UV-vis spectroscopic analyses revealed that with increase in the substrate temperature, the band gap value of the film increases.

Depending on temperature and atmospheric pressure conditions, $\mathrm{ZrO}_{2}$ exists in three polymorphs: monoclinic $\left(m-\mathrm{ZrO}_{2}\right)$ phase which the stable phase from room temperature up to $1100{ }^{\circ} \mathrm{C}$, tetragonal $\left(t-\mathrm{ZrO}_{2}\right)$ phase in the range $1100{ }^{\circ} \mathrm{C}$ to $2300{ }^{\circ} \mathrm{C}$ and cubic $\left(c-\mathrm{ZrO}_{2}\right)$ phase above 2300 ${ }^{\circ} \mathrm{C} .{ }^{12}$ However, at low temperatures, the existence of both tetragonal and cubic metastable phases has been reported by number of research groups. These polymorphic forms depend upon dopants, the presence of impurities, the particle size, the preparatory conditions and precursors.

The present study reports the deposition of $\mathrm{ZrO}_{2}$ thin films on glass substrates by spray pyrolysis technique. The effects of concentration of precursor solution on the structural and optical properties of $\mathrm{ZrO}_{2}$ films were investigated.

\section{Experimental section}

The materials for thin film deposition were zirconyl chloride octahydrate $\left(\mathrm{ZrOCl}_{2} \cdot 8 \mathrm{H}_{2} \mathrm{O}\right)$ and distilled water by SRL, Mumbai. The $\mathrm{ZrO}_{2}$ films were deposited using $\mathrm{ZrOCl}_{2} \cdot 8 \mathrm{H}_{2} \mathrm{O}$ dissolved in distilled water. The precursors were kept ready by varying molarity of solution, thus, four solutions, labeled as $\mathrm{C} 1, \mathrm{C} 2, \mathrm{C} 3$ and $\mathrm{C} 4$ (see Table 1). The flow rate of the carrier gas was $35 \mathrm{~L} / \mathrm{min}$. The distance between the

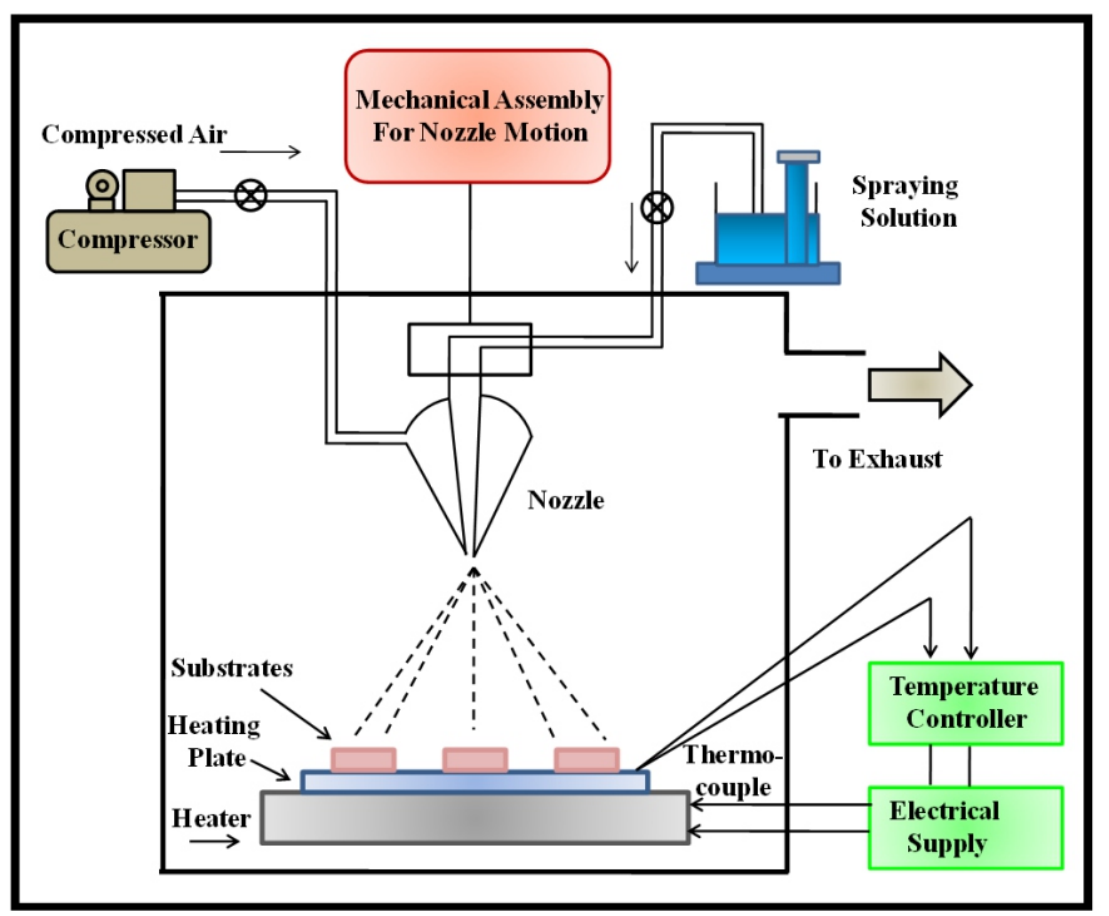

Fig. 1 Schematic of spray pyrolysis technique.

Table 1 Preparatory conditions for the deposition of $\mathrm{ZrO}_{2}$ thin films (different concentration of precursor solution).

\begin{tabular}{cccccc}
\hline Sample & $\begin{array}{c}\text { Concentration } \\
\text { of Solution }\end{array}$ & $\begin{array}{c}\text { Temperature } \\
\left({ }^{\circ} \mathbf{C}\right)\end{array}$ & $\begin{array}{c}\text { Spray Time } \\
(\mathbf{m i n})\end{array}$ & $\begin{array}{c}\text { Spray Rate } \\
(\mathbf{m l} / \mathbf{m i n})\end{array}$ & $\begin{array}{c}\text { Flow Rate } \\
(\mathbf{L} / \mathbf{m i n})\end{array}$ \\
\hline $\mathrm{C} 1$ & $0.025 \mathrm{M}$ & 450 & 2 & 7.5 & 35 \\
$\mathrm{C} 2$ & $0.05 \mathrm{M}$ & 450 & 2 & 7.5 & 35 \\
$\mathrm{C} 3$ & $0.075 \mathrm{M}$ & 450 & 2 & 7.5 & 35 \\
$\mathrm{C} 4$ & $0.1 \mathrm{M}$ & 450 & 2 & 7.5 & 35 \\
\hline
\end{tabular}


substrate and nozzle was $25 \mathrm{~cm}$. The compressed air was used as a carrier gas to spray the precursors at the rate of $7.5 \mathrm{ml} / \mathrm{min}$. The tin bath temperature was maintained as $450{ }^{\circ} \mathrm{C}$ and the glass substrates were kept on it. Fig. 1 shows the schematic of spray pyrolysis technique.

The crystal structure and crystallinity of the deposited films were investigated by X-ray diffraction (XRD). The patterns were obtained on Rigaku "D/B max-2400" ( $\lambda=1.54 \AA$ ) X-ray diffractometer. The surface morphology of the deposited films was observed by scanning electron microscopy (SEM, JEOL-JSM 6360-A). The compositions of the deposited metal oxide films were analyzed by scanning electron microscope (SEM, JEOL-JSM 6360-A) equipped with an energy dispersive X-ray (EDX) detector. Transmission electron microscopic (TEM) investigations were conducted on PHILIPS CM 200 (Operating voltage: $200 \mathrm{kv}$, Resolution: $2.4 \AA$ ) microscope. The optical properties of the $\mathrm{ZrO}_{2}$ thin films were studied in the wavelength region of 200-800 nm using UV-vis spectrometer (JascoV-670). The FT-IR spectra of the $\mathrm{ZrO}_{2}$ thin films were recorded in the range from 400 to $4000 \mathrm{~cm}^{-1}$ in transmittance mode using FT-IR-6100 type A spectrometer.

\section{Results and Discussion}

\subsection{Structural analysis}

The XRD patterns of $\mathrm{ZrO}_{2}$ thin films deposited onto glass substrate at $450{ }^{\circ} \mathrm{C}$ at various concentrations of precursor solution are shown in Fig. 2. The XRD pattern of the as-deposited $\mathrm{ZrO}_{2}$ film (Fig. $2 a$ ) shows that it is amorphous in nature which indicates that the imposing material does not have adequate concentration to produce a crystalline phase. Xiaming et al. ${ }^{16}$ have reported that $\mathrm{ZrO}_{2}$ molecules are formed during the pyrolytic reaction without intrinsic close links at the same substrate temperature. This is an amorphous phase which is very much close to cubic phase of $\mathrm{ZrO}_{2}$. During crystallization, firstly, metastable $c-\mathrm{ZrO}_{2}$ is obtained and then depending upon the preparatory conditions it gets transformed to $m-\mathrm{ZrO}_{2}$ or $t-\mathrm{ZrO}_{2}$. In Fig. $2 b-d$, it is seen that in case of $\mathrm{C} 2$ sample crystallization has begun which increases with increase in concentration. The four major peaks corresponding to (111), (200), (220) and (311) planes confirm the cubic crystal structure in case of all the $\mathrm{ZrO}_{2}$ thin film samples. ${ }^{10,12,14,21}$ All these polycrystalline $\mathrm{ZrO}_{2}$ films are free from impurities as no impurity peaks are observed. The positions of all the peaks are in accordance with the standard $\mathrm{ZrO}_{2}$ data (JCPDS: 27-0997) (see Table 2). The intensity of above peaks increases with increasing concentration of solution up to $0.1 \mathrm{M}$ due to the improvement in crystallinity of the films. The average crystallite size (D) was calculated by the Scherrer formula ${ }^{17}$ using the full width at half maximum (FWHM) of the most intense peak for different samples,

$$
D=\frac{0.9 \lambda}{\beta \cos \theta}
$$

Where, $\beta$ is the FWHM in radians, $\lambda$ is the wavelength used and $\theta$ is the Bragg's angle. The crystallite size of C2, C3 and C4 is $12 \mathrm{~nm}, 9 \mathrm{~nm}$ and $11 \mathrm{~nm}$, respectively. To find the defects in the nanocrystalline $\mathrm{ZrO}_{2}$ films, the dislocation density was calculated using the relation, ${ }^{18}$

$$
\text { Dislocation density }(\delta)=\frac{1}{D^{2}}
$$

The dislocation density was calculated for the given crystallite size. The dislocation density is high for small crystallite due to more number of interfaces in the given volume. The micro strain of the sample was also estimated using the equation, ${ }^{18}$

$$
\text { Micro strain }(\varepsilon)=\frac{\beta \cos \theta}{4}
$$

The micro strain, dislocation density and crystallite size for nanocrystalline $\mathrm{ZrO}_{2}$ films are listed in Table 3.The existence of defects around the lattice could be known from the micro strain. From the observations, it can be concluded that the re-crystallization process in case of polycrystalline films leads to changes in $\delta$ and $\varepsilon .^{15,19}$

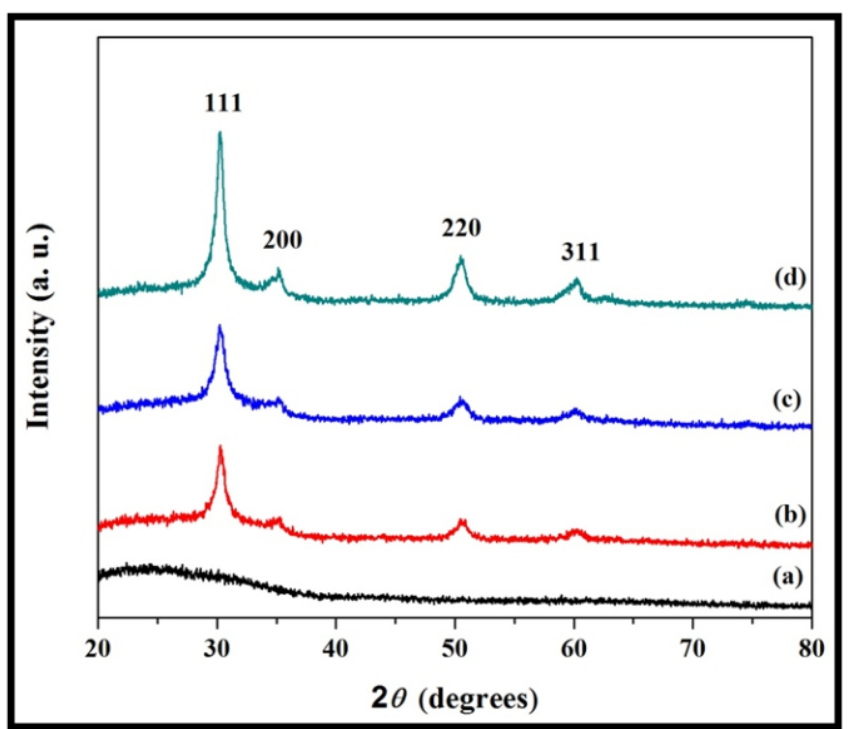

Fig. 2 Influence of concentration of precursor solution on XRD patterns of $\mathrm{ZrO}_{2}$ thin films deposited onto glass substrate at $450{ }^{\circ} \mathrm{C}$ : (a) $0.025 \mathrm{M}$; (b) $0.05 \mathrm{M}$; (c) $0.075 \mathrm{M}$; (d) $0.1 \mathrm{M}$.

\subsection{Surface morphological and elemental analysis}

Fig. 3 shows SEM images of $\mathrm{ZrO}_{2}$ films deposited at different molar concentrations. D. Perednis et al..$^{20}$ have reported that chlorine impurities hinder the crystallization and hence, initially, the films are amorphous in case of chlorides. For $\mathrm{C} 1$, a thin and transparent layer was deposited on the glass substrate. The layer was free from cracks. On the other hand, slightly larger cracks are seen in the films for C4 $(0.1 \mathrm{M})$ solution (Fig. $3 d)$ compared to the $\mathrm{C} 1(0.025 \mathrm{M}), \mathrm{C} 2(0.05 \mathrm{M})$ and $\mathrm{C} 3(0.075 \mathrm{M})$ salt solutions (Fig. $3 a-c$ ). With increase in the concentration of precursor solution, the particle size increases on drying. The spreading of droplets could be the deciding parameter to bring the changes in surface morphology of the films. The roughness of the films is strongly influenced by the rate at which the liquid droplets spread. As viscosity of solution increases that decreases the spreading rate of liquid droplets. In case of the droplets of $\mathrm{C} 1, \mathrm{C} 2, \mathrm{C} 3$ and $\mathrm{C} 4$ concentrated solutions, the spreading of droplets decreases due to increase in viscosity. If rapid drying process is implemented that increases the surface roughness of the films due to incomplete spreading of liquid droplets. It can be concluded that for the deposition of smooth and dense films the concentration of spraying solution should not be too high. However, in order to achieve high deposition rates, a high salt concentration is preferred. It was observed that the increase in salt concentration in the precursor solution increases the surface roughness of the deposited film. The EDX spectra show the presence of $\mathrm{Zr}$ and $\mathrm{O}$ (Fig. 4a-c).

The size and morphology of zirconia samples deposited at $450{ }^{\circ} \mathrm{C}$ were further explored with TEM analyses. Fig. $5 a-c$ show influence of concentration of solution on TEM images of the $\mathrm{ZrO}_{2}$ coatings. The TEM images confirm that the flakes consist of agglomerates of $\mathrm{ZrO}_{2}$ nanoparticles with the average particle size $<20 \mathrm{~nm}$. The selected area electron diffraction (SAED) pattern shows that the formed layer was composed of crystalline $\mathrm{ZrO}_{2}$ nanoparticles (Fig. 5d-f ). Further, the 
Table 2 Comparison of observed $\mathrm{XRD}$ data of $\mathrm{ZrO}_{2}$ thin films obtained after spray pyrolysis at different concentrations of precursor solution with the standard JCPDS data (JCPDS 27-0997).

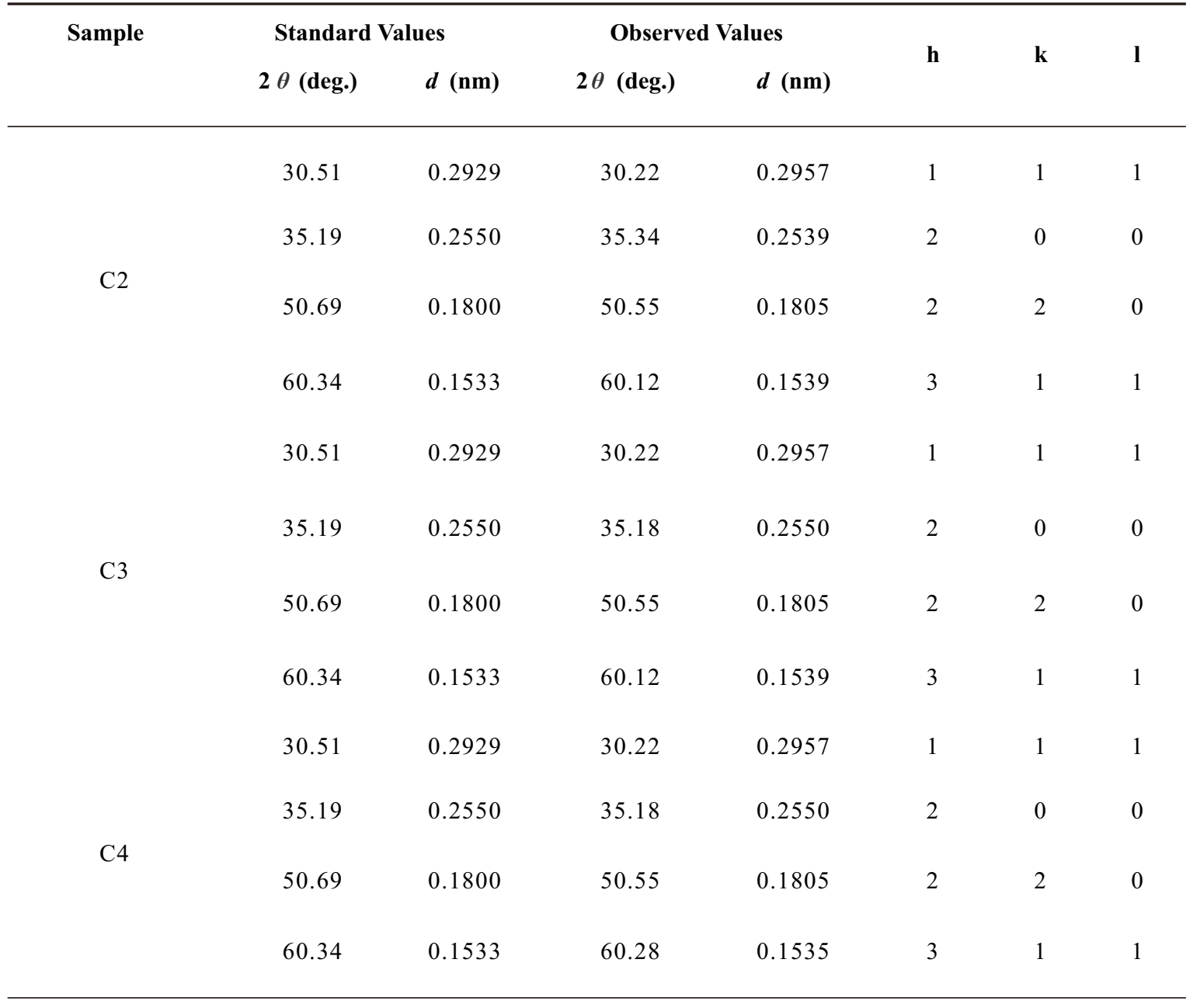

Table 3 Crystallite size, dislocation density and micro strain of $\mathrm{ZrO}_{2}$ thin films obtained at different concentrations of precursor solution.

\begin{tabular}{cccc}
\hline Sample & Crystallite Size, D (nm) & Dislocation Density, $\delta\left(\mathbf{1 0}^{\mathbf{1 4}} \mathbf{~ m}^{-\mathbf{1}}\right)$ & Micro strain, $\varepsilon\left(\mathbf{1 0}^{-4}\right)$ \\
\hline C2 & 12 & 69.44 & 29.57 \\
C3 & 9 & 123.45 & 38.27 \\
C4 & 11 & 82.64 & 31.27 \\
\hline
\end{tabular}



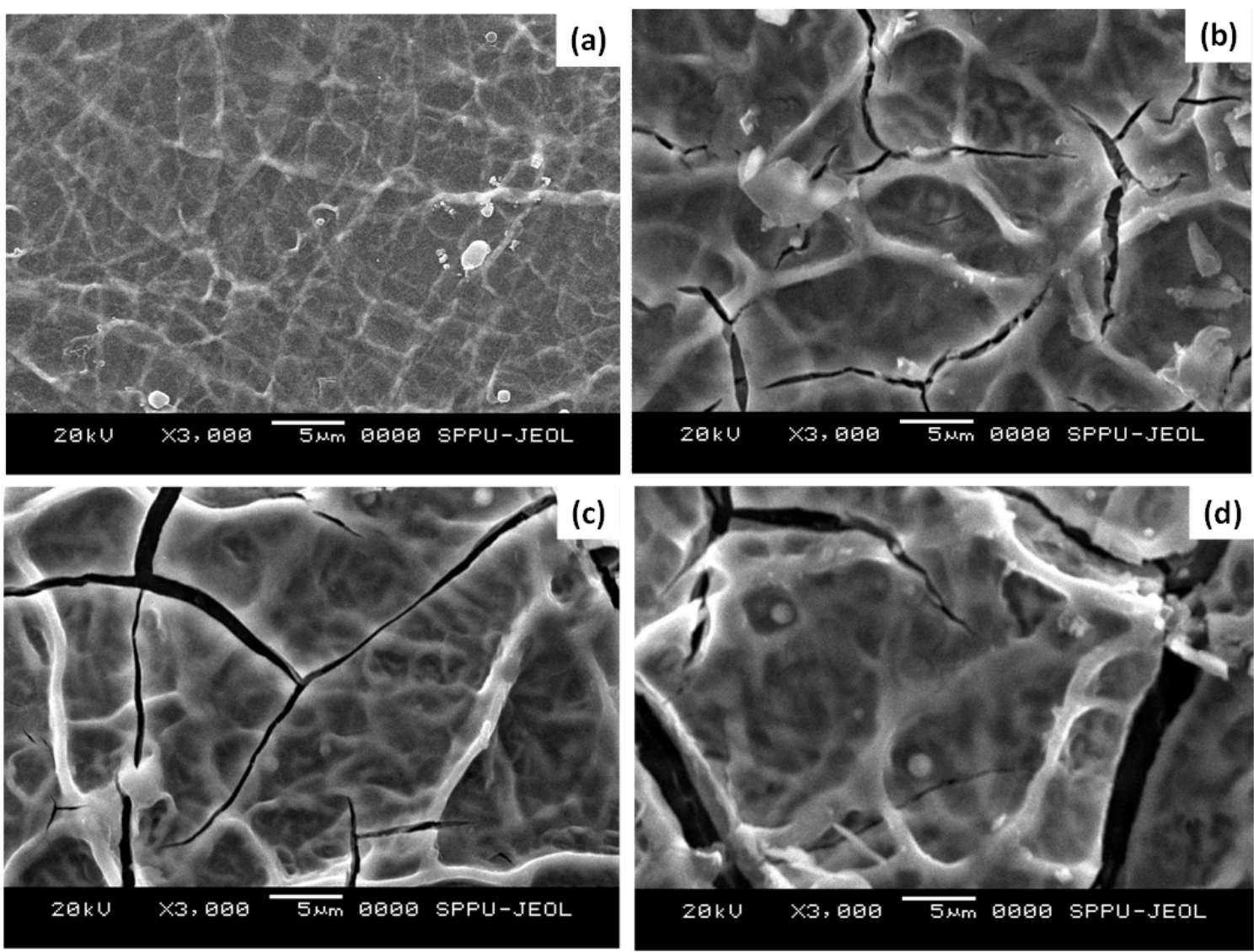

Fig. 3 Scanning electron micrographs of $\mathrm{ZrO}_{2}$ thin films on glass substrate. Deposition condition (concentration of precursor solution): (a) $0.025 \mathrm{M}$; (b) $0.05 \mathrm{M}$; (c) $0.075 \mathrm{M}$; (d) $0.1 \mathrm{M}$.
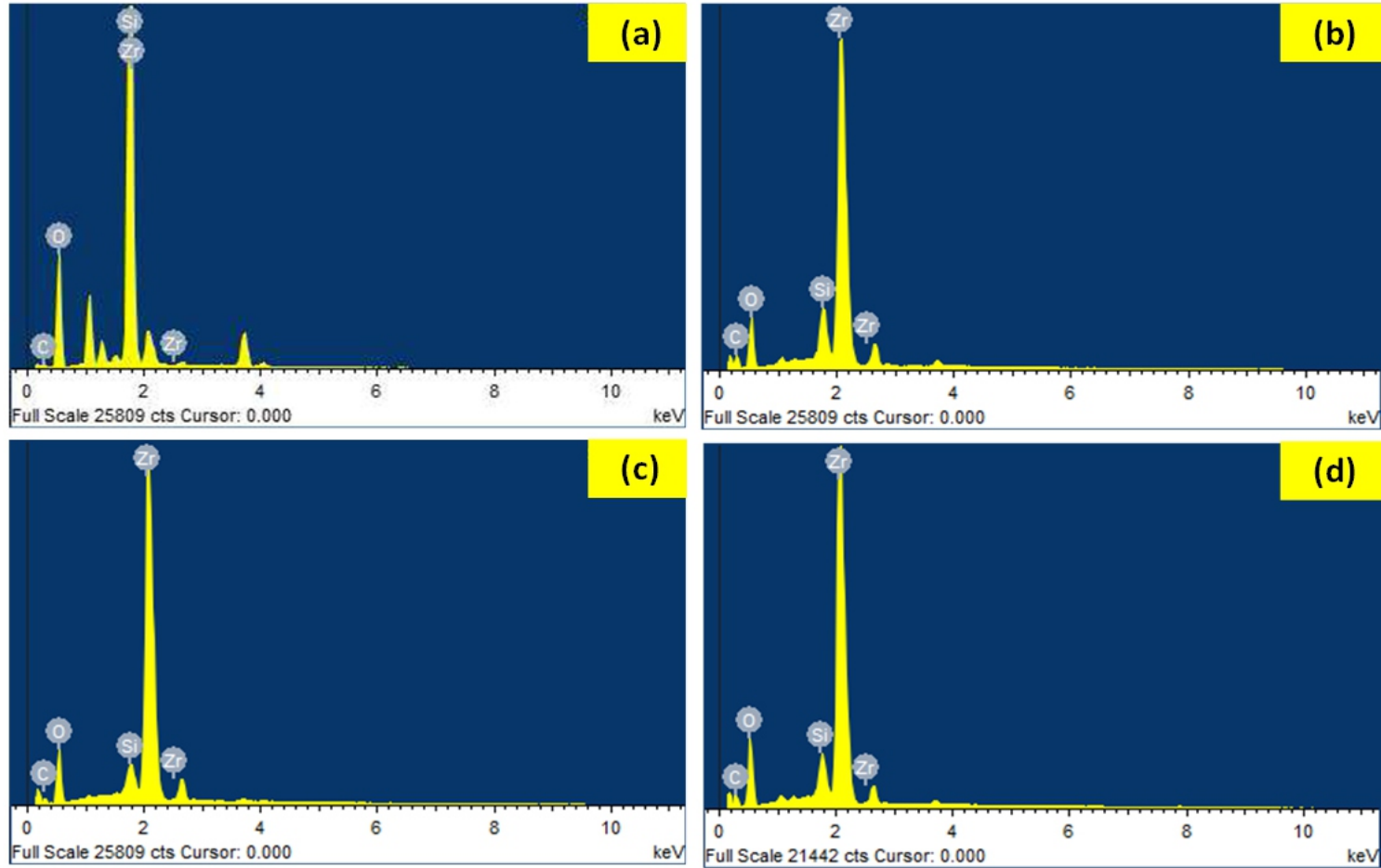

Fig. 4 EDX spectra of $\mathrm{ZrO}_{2}$ thin films on glass substrate. Deposition condition (concentration of precursor solution): (a) $0.025 \mathrm{M}$; (b) $0.05 \mathrm{M} ;(c) 0.075 \mathrm{M} ;(d) 0.1 \mathrm{M}$. 
SAED patterns give spot pattern. However, it seems it is not a single pattern, but a more complex pattern which could be caused by aggregates of nanoparticles. The d-spacing corresponding to the diffraction rings of the SAED patterns is in accordance with the cubic phase of $\mathrm{ZrO}_{2}$ nanocrystals. The SAED patterns of the aggregates of $\mathrm{ZrO}_{2}$ nanoparticles confirm the nanocrystallinity of the films. The concentric Debye-Scherrer rings can be indexed to the (111), (200), (220) and (311) planes and are assigned to the cubic phase. The results show that no phase transformation occurs with increase in concentration of precursor solution. The crystallite size obtained from the X-ray diffraction and TEM results are in good agreement.

\subsection{UV-vis analysis}

The optical absorption measurements were carried out in the wavelength region of $200-800 \mathrm{~nm}$ to estimate the optical band gap energy. The optical band gap $\left(\mathrm{E}_{\mathrm{g}}\right)$ in $\mathrm{ZrO}_{2}$ thin films was estimated using the relationship between the absorption coefficient $(\alpha)$ and the photon energy $(h v)$ given by the equation

$$
\alpha=\frac{A\left(\mathrm{E}_{\mathrm{g}}-h v\right)^{n}}{h v}
$$

where $\mathrm{A}$ is a constant, $\alpha$ is absorption coefficient, $\mathrm{E}_{\mathrm{g}}$ is the band gap energy, and $\mathrm{n}$ is equal to 2 for indirect and $1 / 2$ for direct transition. Fig. 6 shows the plot of $(\alpha h v)^{2}$ versus $h v$ of $\mathrm{ZrO}_{2}$ thin films deposited on glass substrate for different concentration of precursor solution. The optical band gap was determined by extrapolating the straight line portion of the plot to the energy axis for $\alpha=0 .^{21}$ The optical band gap values were found to be $4.18 \mathrm{eV}$ (for $0.1 \mathrm{M}$ concentration), $4.03 \mathrm{eV}$ (for $0.075 \mathrm{M}$ and $0.05 \mathrm{M}$ ) and $4.05 \mathrm{eV}$ (for $0.025 \mathrm{M}$ ). It has been observed that the optical band gap deceases with decrease in concentration of precursor solution. The decrease in optical band gap of the films could be attributed to changes in structural defects, grain size and atomic distances. The improvement in crystallinity and morphology of the film decreases the optical band gap of the material with increase in concentration of precursor solution. ${ }^{22,}{ }^{23}$ The inset of Fig. 6 shows the optical absorption spectra of $\mathrm{ZrO}_{2}$ thin films deposited on glass substrate
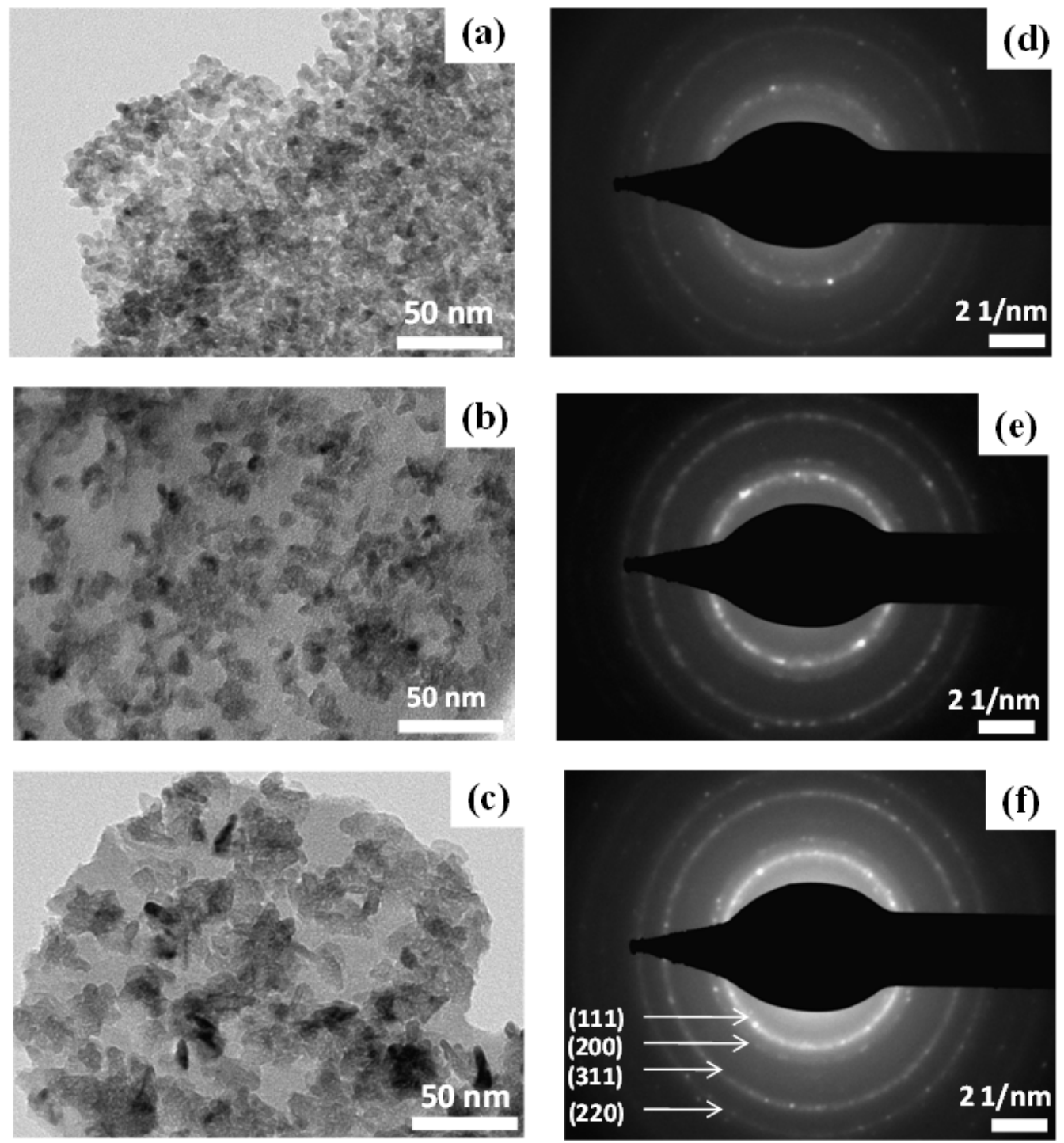

Fig. 5 TEM images of $\mathrm{ZrO}_{2}$ thin films on glass substrate at $450{ }^{\circ} \mathrm{C}$. Deposition condition (concentration of precursor solution): (a) 0.05 $\mathrm{M}$; (b) 0.075 M; (c) 0.1 M. The Corresponding SAED patterns: (d) 0.05 M; (e) $0.075 \mathrm{M}$; $(f) 0.1 \mathrm{M}$. 
at different concentration of precursor solution at $450{ }^{\circ} \mathrm{C}$. In visible region, the optical absorption spectra revealed the low absorbance characteristic feature of $\mathrm{ZrO}_{2}$.

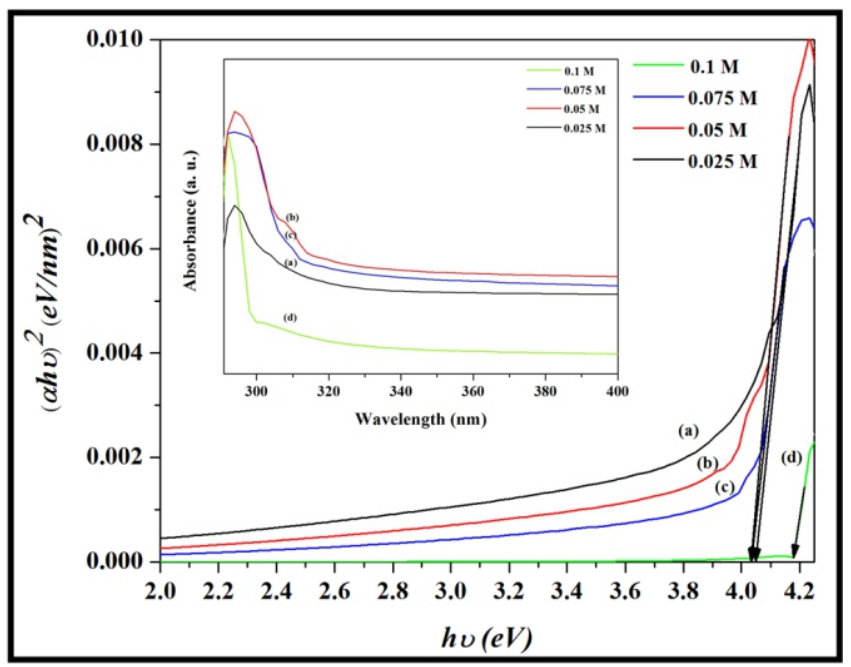

Fig. 6 Variation of $(\alpha h v)^{2}$ versus $h v$ of $\mathrm{ZrO}_{2}$ thin films deposited onto glass substrate at $450{ }^{\circ} \mathrm{C}:(a) 0.025 \mathrm{M},(b) 0.05 \mathrm{M},(c) 0.075 \mathrm{M},(d) 0.1$ $\mathrm{M}$. The inset shows variation in absorbance with wavelength of $\mathrm{ZrO}_{2}$ thin films: (a) 0.025 M, (b) 0.05 M, (c) 0.075 M, (d) 0.1 M.

\subsection{FTIR analysis}

Fig. 7 shows influence of concentration of precursor solution on the FTIR spectra of zirconia films. The $\mathrm{C} 1$ film sample exhibited $\mathrm{O}-\mathrm{H}$ stretching vibration in the frequency range 3406-3908 $\mathrm{cm}^{-1}$ (see Fig. 7a). This could be due to the interaction between $\mathrm{Zr}^{4+}$ and inner hydroxyl groups. This interaction builds superior force of attraction on the stretching vibration due to reduction in the vibrational dipole moment. Hence, in case of $\mathrm{C} 2, \mathrm{C} 3$ and $\mathrm{C} 4$ zirconia film samples the structural vibration for $\mathrm{O}-\mathrm{H}$ were appeared at wave number greater than $3000 \mathrm{~cm}^{-1}$ (see Fig. $7 b-d$ and refer Table 4). The O-H stretching vibrations were observed at $3980,3783,3595$ and $3461 \mathrm{~cm}^{-1}$ in case of C2. In C3 sample, the O-H stretching vibrations were appeared at 3962, 3792,3658 and $3587 \mathrm{~cm}^{-1}$ whereas at 3968, 3778, 3652 and $3601 \mathrm{~cm}^{-1}$ for C4. ${ }^{24}$ The vibrations appeared at 2941, 2932, 2923 and $2937 \mathrm{~cm}^{-1}$ for $\mathrm{C} 1, \mathrm{C} 2, \mathrm{C} 3$ and $\mathrm{C} 4$ respectively which could be ascribed to the impurities in the form of organic residues. ${ }^{26}$ The bands appeared at 2296 $\mathrm{cm}^{-1}$ for $\mathrm{C} 1,2296 \mathrm{~cm}^{-1}$ for $\mathrm{C} 2,2306 \mathrm{~cm}^{-1}$ for $\mathrm{C} 3$ and $2358 \mathrm{~cm}^{-1}$ for $\mathrm{C} 4$ can be attributed to adsorbed $\mathrm{CO}_{2}$ vibrations. ${ }^{27}$ The bands observed at $1589 \mathrm{~cm}^{-1}$ for $\mathrm{C} 1,1598 \mathrm{~cm}^{-1}$ for $\mathrm{C} 2,1582 \mathrm{~cm}^{-1}$ for $\mathrm{C} 3$ and $1549 \mathrm{~cm}^{-1}$ for $\mathrm{C} 4$ could be due to the $\mathrm{N}-\mathrm{O}$ asymmetric stretching vibration. For all samples, the vibration appeared at $1428 \mathrm{~cm}^{-1}$ could be ascribed to $\mathrm{C}-\mathrm{C}$ stretching vibration. ${ }^{28,29}$ The C-N stretching vibrations were observed at $1024 \mathrm{~cm}^{-1}$ for $\mathrm{C} 2,1030$ and $1091 \mathrm{~cm}^{-1}$ for $\mathrm{C} 3$ and 1021 and $1092 \mathrm{~cm}^{-1}$ for $\mathrm{C} 4$. For $\mathrm{C} 1$ and $\mathrm{C} 2, \mathrm{O}-\mathrm{H}$ bending vibration was appeared at 899 and $944 \mathrm{~cm}^{-1}$ respectively. ${ }^{26-29}$
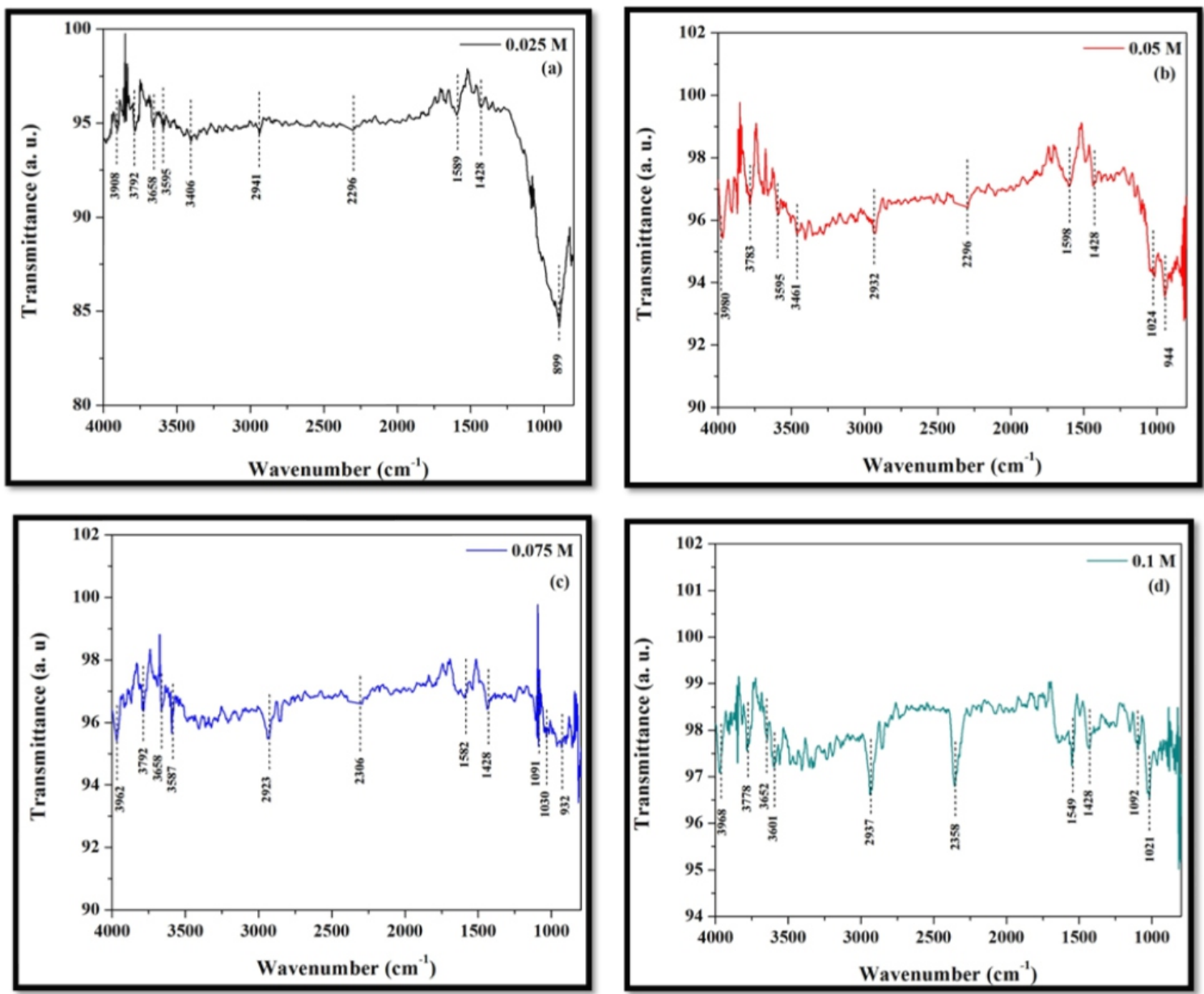

Fig. 7 FT-IR spectra of $\mathrm{ZrO}_{2}$ thin films on glass substrate at $450{ }^{\circ} \mathrm{C}$. Deposition condition (concentration of precursor solution): (a) $0.025 \mathrm{M}$; (b) $0.05 \mathrm{M}$; (c) $0.075 \mathrm{M}$; (d) $0.1 \mathrm{M}$. 
Table 4 IR spectral frequency $\left(\mathrm{cm}^{-1}\right)$ of $\mathrm{ZrO}_{2}$ films with respect to concentration of precursor solution.

\begin{tabular}{|c|c|c|c|}
\hline \multicolumn{4}{|c|}{ Sample } \\
\hline C1 & $\mathrm{C} 2$ & C3 & $\mathrm{C} 4$ \\
\hline 3908 & 3980 & 3962 & 3968 \\
\hline 3792 & 3783 & 3792 & 3778 \\
\hline 3658 & & 3658 & 3652 \\
\hline 3595 & 3595 & 3587 & 3601 \\
\hline 3406 & 3461 & & \\
\hline 2941 & 2932 & 2923 & 2937 \\
\hline 2296 & 2296 & 2306 & 2358 \\
\hline 1589 & 1598 & 1582 & 1549 \\
\hline 1428 & 1428 & 1428 & 1428 \\
\hline & & 1091 & 1092 \\
\hline & 1024 & 1030 & \\
\hline 899 & 944 & 932 & \\
\hline
\end{tabular}

\section{Conclusions}

A precursor solution of zirconyl chloride octahydrate $\left(\mathrm{ZrOCl}_{2} \cdot 8 \mathrm{H}_{2} \mathrm{O}\right)$ can be used to deposit zirconium oxide films by spray pyrolysis technique. The influence of concentration of precursor solution on the structural and optical properties of $\mathrm{ZrO}_{2}$ films were investigated by XRD, SEM, EDX, TEM, UV- vis and FT-IR techniques. XRD analyses demonstrated that the films prepared at lower concentration $(0.025 \mathrm{M})$ were found to be in amorphous phase. The increase in concentration from $0.05 \mathrm{M}$ to $0.1 \mathrm{M}$ of precursor solution increases the crystallinity of the films. Only cubic zirconia $\left(c-\mathrm{ZrO}_{2}\right)$ phase was indentified in all the crystalline film samples at substrate temperature of $450{ }^{\circ} \mathrm{C}$. TEM studies showed that the average particle size in all film samples was $<20 \mathrm{~nm}$. The SAED patterns showed that films composed of crystalline cubic $\mathrm{ZrO}_{2}$ nanocrystals. The optical band gap values of the deposited films were increased with increase in concentration of precursor solution. The formation of $\mathrm{ZrO}_{2}$ was further confirmed by FT-IR studies.

\section{Conflicts of interest}

There are no conflicts to declare

\section{Acknowledgements}

Authors are thankful to Board of College and University Development (BCUD), Savitribai Phule Pune University, Pune for financial support under the project.

\section{References}

1. D. H. Kuo and C. H. Chien, Thin Solid Films, 2003, 429, 40-45.

2. S. Zhao, F. Ma, K. W. Xu and H. F. Liang, J. Alloys Compd., 2008, 453, 453-457.

3. A. P. Huang and P. K. Chu, Mater. Sci. Eng. B, 2005, 121, 244-247.

4. M. Asilturk, E. Burunkaya, F. Sayılkan, N. Kiraz and E. Arpaç, J. Non-Cryst. Solids, 2011, 357, 206-210.

5. K. Joy, I. J. Berlin, P. B. Nair, J. S. Lakshmi, G. P. Daniel and P. V. 
Thomas, J. Phys. Chem. Solids, 2011, 72, 673-677.

6. H. Tomaszewski, J. Haemers, J. Denul, N. De Roo and R. De Gryse, Thin Solid Films, 1996, 287, 104-109.

7. J. C. Delgado, F. Sánchez, R. Aguiar, Y. Maniette, C. Ferrater and M. Varela, Appl. Phys. Lett., 1996, 68, 1048-1050.

8. Z. Chen, N. Prud'homme, B. Wang and V. Ji, Surf. Coat. Technol., 2011, 206, 405-410.

9. D. Nguyen, M. van Roode and S. Johar, Thin solid films, 1986, 135, L19-L21.

10. H. Ruiz, H. Vesteghem, A. R. Di Giampaolo and J. Lira, Surf. Coat. Technol., 1997, 89, 77-81.

11. N. H. J. Stelzer and J. Schoonman, J. Mater. Synth. Process, 1996, 4, 429-438.

12. P. Peshev, I. Stambolova, S. Vassilev, P. Stefanov, V. Blaskov, K. Starbova and N. Starbov, Mater. Sci. Eng. B, 2003, 97, 106-110.

13. A. Ortiz, J. C. Alonso and E. Haro-Poniatowski, J. Electron. Mater., 2005, 34, 150-155.

14. A. I. Ramos-Guerra, J. Guzman-Mendoza, M. García-Hipólito, O. Alvarez-Fregoso and C. Falcony, Ceram. Int., 2015, 41, 1127911286.

15. M. Jothibas, C. Manoharan, S. J. Jeyakumar, P. Praveen and I. J. Panneerdoss, J. Mater. Sci. - Mater. Electron., 2016, 27, 58515859.

16. D. Xiaming, L. Qingfeng and T. Yuying, J. Am. Ceram. Soc., 1993, 76, 760-762.

17. B. D. Cullity, Elements of X-ray Diffraction, Addison-Wesley Publishing Company, Inc., London, 1978, 99.
18. A. U. Ubale and M. R. Belkhedkar, J. Mater. Sci. Technol., 2015, 31, 1-9.

19. M. Jothibas, C. Manoharan, S. Ramalingam, S. Dhanapandian, S. J. Jeyakumar and M. Bououdina, J. Mol. Struct., 2013, 1049, 239249.

20. D. Perednis, O. Wilhelm, S. E. Pratsinis and L. J. Gauckler, Thin solid films, 2005, 474, 84-95.

21. B. Karunagaran, R. T. Rajendra Kumar, C. Viswanathan, D. Mangalaraj, S. K. Narayandass and G. Mohan Rao, Cryst. Res. Technol., 2003, 38, 773-778.

22. Y. Akaltun, M. A. Yıldırım, A. Ateş and M. Yıldırım, Opt. Commun., 2011, 284, 2307-2311.

23. S. Visalakshi, R. Kannan, S. Valanarasu, H. S. Kim, A. Kathalingam and R. Chandramohan, Appl. Phys. A, 2015, 120, 1105-1111.

24. D. Sarkar, D. Mohapatra, S. Ray, S. Bhattacharyya, S. Adak and N. Mitra, Ceram. Int., 2007, 33, 1275-1282.

25. G.Y. Guo and Y. L. Chen, J. Mater. Chem., 2001, 11, 1283-1287.

26. A. J. Maira, K. L. Yeung, J. Soria, J. M. Coronado, C. Belver, C. Y. Lee and V. Augugliaro, Appl. Catal. B-Environ., 2001, 29, 327336.

27. M. A. Waghmare, K. S. Pawar, H. M. Pathan and A. U. Ubale, Mater. Sci. Semicond. Process., 2017, 72, 122-127.

28. C. M. Phillippi and K. S. Mazdiyasni, J. Am. Ceram. Soc., 1971, 54, 254-258.

29. S. Chen, Y. Yin, D. Wang, Y. Liu and X. Wang, J. Cryst. Growth, 2005, 282, 498-505. 